\title{
IMPOSSIBILIDADE E IMPOTÊNCIA: TRAJETÓRIAS DA REPRESENTAÇÃO EM CLARICE LISPECTOR
}

\author{
Impossibility and impotence: \\ representation paths in Clarice Lispector
}

Flávia Trocoli Xavier da Silva*

\section{Prelúdio: "O horror sou eu diante das coisas"}

I

nicio com uma breve comparação entre encontros com a alteridade que ocorrem nas seguintes obras de Clarice Lispector: Perto do coração selvagem, 1944, hora da estrela, 1977. Penso que tanto os encontros de Joana com a tia, com Otávio e com Lídia, quanto os encontro de Martim com Vitória e com Ermelinda, sejam um confronto com o outro, mas se comparo tais confrontos em Perto do coração selvagem e em A maçã no escuro com aqueles que ocorrem em A paixão segundo G.H. (doravante $P S G H$ ) e em $A$ hora da estrela (doravante $H E$ ), diriaque existe algo de bastante específico nesse outro que é o umbigo da cena: a barata e Macabéa. Os encontros que ocorrem em Perto do coração selvagem e em A maçã

* Doutora pela Unicamp. 
no escuro podem ser situados no plano do mal-entendido, da equivocidade e do descompasso entre aqueles que falam, que trocam uma coisa pela outra, que metaforizam. Estão em acordo com o que em Água viva foi chamado de "vida oblíqua":

\begin{abstract}
A vida oblíqua? Bem sei que há um desencontro leve entre as coisas, elas quase se chocam, há um desencontro entre os seres que se perdem uns aos outros entre palavras que quase não dizem mais nada. Mas quase nos entendemos nesse leve desencontro, nesse quase que é a única forma de suportar a vida em cheio, pois um encontro brusco face a face com ela nos assustaria, espaventaria os seus delicados fios de teia de aranha. Nós somos de soslaio para não comprometer o que pressentimos de infinitamente outro nessa vida de que te falo. Lispector (1998b, p. 74)
\end{abstract}

Em contrapartida, em $P S G H$ e em $H E$ se vai do oblíquo ao face a face. A barata e Macabéa são a ênfase radical naquilo que paradoxalmente a literatura clariciana tenta emoldurar com palavras, isto é, justamente aquilo que resiste à captura pela palavra. Em outras palavras, tanto em $P S G H$ como em $H E$, os narradores, G.H., no primeiro, e Rodrigo S.M., no segundo, estão posicionados diante de um outro radical que tanto escapa à representação quanto a desencadeia. Ambos os encontros produzem efeitos determinantes para a escritura dos textos. Delinearei o que há de específico nos impasses que a barata e Macabéa colocam para em seguida traçar os efeitos desses encontros com o indizível na escritura dos textos.

\title{
Linguagem e perda em A paixão segundo G.H.
}

Antes de nos confrontarmos com a barata, é preciso passar pela empregada que, através do quarto vazio e do mural na parede, estilhaça a continuidade dos dias, dos pensamentos e das expectativas de G.H. E, doravante, faz com que se sinta subordinada a uma alteridade que a faz enxergar de um lugar que esvazia todas as suas identificações: escultora, solteira, sem filhos, pertencente à classe média alta carioca. Tais identificações equivalem à "terceira perna" que tanto a estabilizava quanto mascarava o vazio que, na seqüência dos eventos, é tomado como constituinte. 
Mas o que essa descontinuidade, esse hiato aberto pela empregada tem a ver com o surgimento da barata? O que se pode dizer é que na seqüencia dos dois eventos, a ligação inextricável presente no fato que é no quarto da empregada que se encontra a barata, constata-se um desmascaramento do vazio, para que algo de um real indizível pudesse emergir.

G.H. ajuda a pensar a especificidade da barata quando liga o acontecido no quarto da empregada a um retorno, a um esquecido que retorna, e me conduz às palavras de Jeanne Marie Gagnebin referindo-se a certa linhagem de personagens kafkianas:

...enquanto manifestações do esquecimento, essas personagens são testemunhas de um mundo primitivo 'hetaírico, 'préhistórico', que não conseguimos integrar e que só pode surgir como uma ameaça imemorial; mas elas só são verdadeiramente assustadoras porque tiveram de ser esquecidas, recalcadas, diz Benjamin. Gagnebin (1994, p. 78)

Esse não-dito que a barata atualiza atinge o ponto de indizibilidade radical no momento em que G.H. coloca a massa branca da barata na boca. O gozar da barata através da devoração, gozo que deveria ter permanecido perdido, faz desaparecer o descontínuo, obtura a falta, impossibilita a fala e lança o sujeito no indistinto angustiante:

...uma forma dá construção à substância amorfa - a visão de uma carne infinita é a visão dos loucos, mas se eu cortar a carne em pedaços e distribuí-los pelos dias e pelas fomes - então não será mais a perdição e a loucura será de novo a vida humanizada. Lispector (1998a, p. 14) [grifo meu]

E se comer aponta tanto para o literal, para aquilo que não admite metáforas, quanto torna imperiosa a representação, vomitar também aponta para tal divisão. Vomitar a barata, além de ser literalmente vomitá-la, é também, simbolicamente, recuperar a possibilidade de dar forma, de representar. Vomitá-la reinstaura a divisão entre o gozo não-simbolizável e a palavra que não cessa de tentar inscrevê-lo.

Através da incorporação, G.H. se vê confrontada com o impossível: o nada, lugar onde nada falta. Acontecimento que ultrapassa o arsenal de compreensão do 
sujeito e torna-se um enigma. Diria que em $P S G H$, não se trata de decifrar o enigma, mas de configurá-lo. Primeiramente, G.H. diz que desprezará as palavras e só poderá "fazer a transcrição fonética" do que lhe aconteceu. Tal desejo de literalização me remete às palavras de Lúcia Castello Branco sobre a escritora portuguesa Maria Gabriela Llansol, a qual a ensaísta situa na mesma linhagem de Clarice Lispector e Marguerite Duras:

Entrar no mundo onde o cão é cão reduz-se, afinal, a toda tentativa de Llansol com sua escrita, em que uma "rapariga que teme a impostura da língua" busca atingir uma linguagem sem impostura, um mundo sem metáforas onde as coisas são o que são e a palavra não é mais que a pele delicada, a delicada película que as recobre:... Branco $(2000$, p. 21$)$

E mal se inicia tal busca de uma linguagem sem impostura, para saber que a palavras não se relacionam de maneira transparente e inequívoca com a coisas. Lêse em Água viva: "nesta densa selva de palavras que envolvem espessamente o que sinto e penso e vivo e transforma tudo o que sou em alguma coisa minha que no entanto fica inteiramente fora de mim" (Lispector, 1998b, p. 61-62). Dito isso, já se pode marcar duas dimensões de perda que a linguagem evoca: 1) perda da esperança em uma linguagem literal destituída de seus processos metafóricos e metonímicos; 2) perda da ilusão de autonomia do sujeito em relação à linguagem. Passo, então, aos efeitos de tais perdas sobre o texto.

Conforme exposto, o gozar da barata se dá através da manducação. Gozo que vinculo à literalidade, uma vez que resiste à metaforização e à produção de sentidos. Este gozo provoca a cogitação de G.H. sobre a dimensão de loucura do que lhe aconteceu. Loucura que G.H. associa diretamente ao contínuo, ao que não comporta a palavra que, inevitavelmente, segmenta. Estar em continuidade com a "própria coisa" é justamente consisti-la sem nomeá-la, sem ultrapassá-la:

Sentada, consistindo, eu estava sabendo que se não chamasse as coisas de salgadas ou doces, de tristes ou alegres ou dolorosas ou mesmo com entretons de maior sutileza - que só então eu não estaria mais transcendendo e ficaria na própria coisa. Essa coisa cujo nome desconheço, era essa coisa que, olhando a barata, eu já estava conseguindo chamar sem nome. Lispector (1998a, p. 86) 
Ao estar "consistindo", G.H. não "sabe", mas "estava sabendo", pois "consistir" não admite um saber no presente. O que consiste interdita o dizer que já provocaria um deslocamento e um corte. Só se sabe que se "consistiu" no "só depois" em que o impossível já está perdido, e daí consistir já não mais "é" pois já "está" na cadeia de siginificações. E, então, se pode dizer com Lacan que "é na cadeia significante que o sentido insiste, mas que nenhum dos elementos da cadeia consiste na significação de que ele é capaz nesse momento" (Lacan, 1998, p. 505)

E é somente às custas da errância da palavra, das repetições, das associações, das substituições que o indizível encontra uma possível e parcial dizibilidade. Portanto, a "carne infinita" e perdida transmuta-se 1) em oscilação significante, como por exemplo, as designações para a experiência que vão: do divino ao diabólico, do inferno ao paraíso, da vida à morte, da repulsa ao fascínio; 2) em ambivalência, exemplos: "nojo fascinante", "morte vivificadora"; e 3) em substituição: neutro, nada, nó vital. Errância e polissemia são efeitos do trajeto do consistir impossível ao insistir em significantes sempre parciais.

A desistência da qual a narradora fala no final do relato poderia ser pensada como reconhecimento tanto de uma impossibilidade de literalização do acontecimento, em que a linguagem se destituísse da metáfora, quanto de que, como dirá G.H., só se terá a mudez através da voz, o vazio através da linguagem, a coisa através de um pedaço de coisa:

Olha só o que é tudo: é um pedaço de coisa, é um pedaço de ferro, de saibro, de vidro. Eu me disse: olha pelo que lutei, para ter exatamente o que eu já tinha antes, rastejei até as portas se abrirem para mim, as portas do tesouro que eu procurava: e olha o que era meu tesouro! O tesouro era um pedaço de metal, era um pedaço de cal da parede, era um pedaço de matéria feita em barata. (...) Minha exaustão se prostrava aos pés do pedaço de coisa, adorando infernalmente. $\mathrm{O}$ segredo da força era a força, o segredo do amor era o amor - e a jóia do mundo é um pedaço opaco de coisa. Lispector (1998a, p. 136-137)

Neste fragmento, embora não se localize a elisão do significante que designa a coisa, ocorre uma operação homológa a um processo metonímico: a coisa substituída por um pedaço de coisa, a barata substítuida por sua antena, a parede substituída pela caliça. Primeiramente, vê-se marcada a perda da coisa. E, na substituição, um deslocamento é enfatizado, o segredo não está na coisa, mas em suas partes. Ter na boca a massa branca da barata é o mais absoluto silêncio. Mas perder é possibilidade de ter o segredo crispado de subtrações, mas configurado. 
O romance divide-se em trinta e três seções e o fragmento que acabo de ler está situado na vigésima quarta seção do texto. À sua luz, retorno às seções anteriores e observo que, de certa maneira, a operação metonímica já se iniciara na sexta seção, quando G.H. prende a barata na porta do armário. Daí em diante, em diversos momentos, a barata será designada através de sua divisão: "Prendendoa pelo meio do corpo, (...)"; "A barata de súbito vomitou pela sua fenda mais um surto branco e fofo."; "Também ao sol estava a barata bipartida."; "Eu só a pensara como fêmea, pois o que é esmagado pela cintura é fêmea." O contínuo se divide, o neutro é também fêmea. Ou seja, é dilacerado que o vivo participa do reino da palavra.

Vilma Arêas, em $O$ resto da metafísica, antes de acompanhar a feitura do poema Tabacaria, 1928, de Álvaro Campos, heterônimo de Fernando Pessoa, fornece algumas coordenadas de leitura que, se apagasse a referência a Pessoa, poderia dizer referentes a Clarice: a tessitura de vozes; a impossibilidade de redução de qualquer uma dessas vozes que compõem a obra a uma única face, aqui é importante citar: “(...) e na direção de Beckett anos depois falando do próprio trabalho, a obra é completa em sua totalidade fragmentada, irredutível a qualquer um dos lados." Arêas (texto inédito); o fato da coisa vista jamais residir na coisa dita, sempre numa relação de sobra ou de falta e por fim a evidência do paradoxo da arte em sua relação de proximidade e distância quanto ao vivido.

Como efeito de todas as características enumeradas, o texto do poema se apresenta cindido entre um que está para ser feito no futuro, portanto não-existente (texto-1) e o outro (texto-2) que "é dado como o contexto do texto-1, como uma situação matéria-prima do texto-1; tal texto-2 está e é fingido ausente sob a forma de poema, porque está como o antes do poema" Arêas (texto inédito). Se até aqui segui os passos do ensaio de Vilma Arêas, doravante dele me separo, pois não poderia fazer acompanhar a construção do poema de Campos com a construção do texto de G.H..

O que fica é que cisão homóloga também pode ser apreendida no texto de G.H. que estaria cindido entre um texto que pertenceria ao registro do real indizível, ainda a ser escrito, não-existente, e outro texto, aquele que lemos, inscrito no registro simbólico e que seria uma metonímia do primeiro. Poderia estabelecer uma relação metafórica entre a barata-coisa e o texto literal-impossível, e entre o texto metonímico e o "segredo" que a narradora descobre num "pedaço de coisa", numa "antena de barata". Ou seja, o texto-metonímico pode ser escutado como uma evocação reiterada da possibilidade perdida de inscrição simbólica do texto literal-impossível, que se faz presente enquanto objeto perdido. Eis a poética da fragmentação que se delineia em PSGH. 


\title{
"Resto cantável": a crise da literatura em $\boldsymbol{A}$ hora da estrela
}

Inicialmente, o corpo de Macabéa aponta para aquilo que escapa ao campo metafórico, no entanto o fato dele ser visto da perspectiva do narrador - ponto de irradiação da representação - faz com que ele se torne fonte de metáforas.

Assim, as metáforas corporais produzidas pelo narrador de $H E$ manifestam a dor de viver e de escrever: "A dor de dentes que perpassa esta história deu uma fisgada funda em plena boca nossa."; "A vida é um soco no estômago"; "Será que o meu ofício doloroso é o de adivinhar na carne a verdade que ninguém quer enxergar?" Paradoxalmente, as palavras do narrador apontariam para uma lucidez que, em consonância com as percepções de Macabéa, não se articularia em palavras mas estaria sim impressa na dor. O grito, presente em um dos títulos, seria a marca de insuportabilidade dessa dor de dentina exposta que percorre a narrativa como suplemento para as palavras que Macabéa não articula. Ainda que engendradas por outros textos, as palavras de Márcio Seligmann-Silva apontam uma dimensão fundamental de $H E$. Vale a pena a longa citação:

\begin{abstract}
Se recordarmos com Jean Améry, que "a dor é a intensificação mais elevada de nossa corporeidade (Körperlichkeit) que podemos pensar", que nela ocorre a redução à equação "corpo = dor $=$ morte", compreendemos a gravidade do fato de que é nesse achatamento da existência que Adorno vai buscar a última referência possível à experiência, sem a mentira da abstração. A memória da dor deve servir de arma para garantir que este mesmo corpo não seja novamente torturado. (...) Não só a ética, para Adorno, fica condenada a se rearticular a partir do frágil corpo humano, mas também a arte - que ele já pensara antes da Segunda Guerra Mundial na chave da representação do sofrimento - mais do que nunca deve ser pensada a partir do corpo e da expressão da sua dor. Seligmann-Silva (2003, p. 78-79)
\end{abstract}

Em $H E$, o corpo convocado parece ser também o corpo nauseado do próprio leitor ao ser confrontado com os "retratos" de Macabéa. O narrador, no lugar de nos descrever a imagem corporal de Macabéa refletida no espelho, nos dá um espelho vazio e, até aqui o "retrato" poderia ser também o de G.H. ou o do próprio narrador, no entanto o traço de diferença não tarda a aparecer, algo se reflete na pia: "Olhouse maquinalmente ao espelho que encimava a pia imunda e rachada, cheia de cabelos, 
o que tanto combinava com a sua vida. Pareceu-lhe que o espelho baçonãorefletia imagem alguma." (Lispector, 1998c, p. 25). Outro "retrato", agora através de Olímpico: “- Você, Macabéa, é um cabelo na sopa. Não dá vontade de comer." (Lispector, 1998c, p. 60). Mas se Olímpico falou da repugnância que Macabéa provocava, as colegas de quarto não lhe disseram que ela cheirava mal. Mas o leitor sabe. E sabe também que além de repugnante, seu corpo é duplamente inútil, pois não serviria para a prostituição e tampouco para a gravidez, seus "óvulos são murchos como cogumelos cozidos." (Lispector, 1998c, p. 58). Macabéa não é fértil, mas também não é assexuada: "Penso no sexo de Macabéa, miúdo mas inesperadamente coberto de grossos e abundantes pêlos negros - seu sexo era a única marca veemente de sua existência." (Lispector, 1998c, p. 70). Se para o corpo neutro, há possibilidade de sexuação, para a fome, há possibilidade de se transformar em desejo.

O desejo aparece, em $H E$, como um dos últimos indícios da vida: "até no capim vagabundo há desejo de sol" (Lispector, 1998c, p. 28), "Ela nada pedia mas seu sexo exigia, como um nascido girassol no túmulo" (Lispector, 1998c, p. 70). No incessante dizer e desdizer do narrador, que engendra uma fragmentação diferente daquela apreendida em $P S G H$, a fome ora liga-se à comida e reduz-se à necessidade, ora ganha dimensão metafórica e passa à dimensão do desejo. Num momento, o pote de creme para pele, se pudesse ser comprado, seria comido. Noutro, Macabéa perde o apetite de comida e só lhe resta "a grande fome" (Lispector, 1998c, p. 39). Em outras palavras, Macabéa, ainda que "vagamente", toma conhecimento e pensa e finge, a fome não se reduz à necessidade, portanto pode ser chamada de desejo: "Era assim: ficava faminta mas não de comida, era um gosto meio doloroso que subia do baixo-ventre e arrepiava o bico do seio e os braços vazios sem abraço" (Lispector, 1998c.) [grifos meus].

Logo, a obra intitulada $A$ hora da estrela, além de mostrar pela redução à dor e ao corpóreo o "achatamento da existência" acima mencionado,também teria como função pressupor uma subjetividade onde, à primeira vista, existiria apenas uma "vinculação quase integral ao biológico" (Pontieri, 1999, p. 44). Sob um outro ângulo, Macabéa também é lugar onde se inscreve a divisão, a falta, o desejo.

Apesar desses indícios de subjetividade apontados pelo narrador, Macabéa não pode tomar a palavra e tornar-se sujeito da enunciação. Esta impotência de Macabéa provoca a impotência do narrador, uma vez que as palavras ditas por ele não são eficazes a ponto de transformar a impotência de Macabéa em impossibilidade. A linguagem se afasta de qualquer performatividade. A crise da literatura está configurada: "Quanto a escrever, mais vale um cachorro vivo." (Lispector, 1998c, p. 35). Em $H E$, escrever é reunir os cacos deixados pela impossibilidade de ação concreta, uma vez que a literatura não transforma a impotência de Macabéa em impossibilid ade. Impossibilidade entendida como aquilo 
que não foi capturado pelo dizer, ponto nevrálgico de $P S G H$. Impotência entendida como não poder dizer, ponto nevrálgico de $H E$.

A subjetividade desse outro que não pode dizer faz apelo a uma ética em que fica vetada àquele que pode enunciar toda possibilidade de "explicação e compreensão". Falar sobre a subjetividade de um outro radical produz um texto contraditório, lacunar, fragmentado, pois jamais o narrador saberá tudo daquilo que lhe é outro. Jamais poderá entender a subjetividade desse outro como coextensiva à sua própria e preencher as lacunas do não-entendimento com uma sonsa compreensão. E então, pode-se concordar com Maurice Blanchot: "A arte não lhe deu esse infortúnio, nem mesmo o ajudou a isso mas, pelo contrário, esclareceu-o, 'foi a consciência da infelicidade', a sua nova dimensão. A arte é, em primeiro lugar, a consciência da infelicidade, não a sua compensação.” (Blanchot, 1987, p. 69).

\section{Impotência e impossibilidade: distinguindo duas escrituras}

Localizar uma tonalidade melancólica na escritura clariciana como efeito de uma crise e evocação da perda, poderia situar Clarice Lispector numa determinada linhagem da modernidade. A melancolia compareceria não pela via da patologia ou do psicológico como já adiantara Plínio Prado Jr., ${ }^{1}$ mas como uma figuração que condensa temas fulcrais para a modernidade: a reiterada ênfase na perda da possibilidade de representação inequívoca e plena, a ironia, a morte.

Em De l'hospitalité, Derrida, ao ocupar-se da leitura de Édipo em Colono, enfatiza a impossibilidade de luto de Antígona e Ismene diante do desconhecimento do lugar do túmulo de Édipo. E, diz ainda, que o choro de Antígona é antes pela privação do luto do pai do que pela morte em si, o que acaba por votá-la a um luto infinito. Ou seja, melancólico. Nessa leitura, poderíamos pensar a condição de Antígona como a condição da própria escritura como refém do não-sentido, das descontinuidades, dos vazios e dos lamentos engendrados pelo tempo, pelo outro, pela linguagem, pela história.

A partir da iconografia melancólica, Lambotte tematiza o desespero melancólico face aos limites do pensamento: "A Melancolia brinca com um compasso tornado fundamentalmente inútil e seu olhar se perde nos confins da

1 PRADO JR., Plínio. O impronunciável: notas sobre um fracasso sublime. Remate dos males. Campinas, 1989. 
impotência." (Lambotte, 2000, p. 51). Sim, A hora da estrela pode ser lida pelo prisma da melancolia, mas delinearei melhor sua especificidade comparando-a com A paixão segundo G.H.. Impotência (fundante em $H E$ ) e impossibilidade (reveladora em $P S G H$ ) seriam as duas dimensões em que se inscrevem e se distinguem as narrativas de $P S G H$ e de $H E$. Sendo que em $H E$, as duas dimensões coexistem e ganham proporções mais acentuadas. Sim, em $P S G H$, a protagonista também esbarra nos limites do pensamento e no nada, instauradores de um não-saber implacável. Não-saber que, no entanto, ganha uma dimensão de revelação e ultrapassamento libertador, ou seja, a conjuntura da perda pela qual G.H. passa poderia ser tomada como melancólica, o que no entanto não se consuma, visto que é redimensionada pela possibilidade de dizer. Ouçamos mais uma vez: "A vida se me é, e eu não entendo o que digo. E então adoro. ——" (Lispector, 1998a, p. 179). Rodrigo S.M., narrador de $H E$, não adora, se exaspera. E, no lugar do compasso inútil para a medição e o cálculo, tem em sua mão a pena impotente, mas não pode ceder ao silêncio, ao branco da folha. A impotência da palavra e a impossibilidade de calar engendram a contradição. Existem cacos e restos clamando por uma forma, não por um sentido, este definitivamente não há. A literatura não pagará a dívida, apenas lhe dará uma moldura.

\section{RESUMO}

A barata, em A paixão segundo G.H., 1964, e Macabéa, em A hora da estrela, 1977, são a ênfase radical naquilo que resiste à captura pela palavra e provocam efeitos distintos na escritura dos textos. Atrelando linguagem, alteridade e subjetividade, o ensaio analisa comparativamente a função que a palavra assume em cada uma das obras mencionadas. Função que remete à possibilidade ou à impossibilidade de representação do real e a uma possível melancolização daí decorrente. Em A paixão segundo G.H., a narradora-protagonista depara-se com a impossibilidade de representação. Impossibilidade que, através da configuração de uma verdadeira poética da fragmentação, ganha uma dimensão de revelação e libertação. Em $A$ hora da estrela, diante da personagem que não pode se tornar sujeito da enunciação e que nem por isso vincula-se integralmente ao biológico, a palavra torna-se impotente e, no entanto, é impossível calar. A fragmentação e a contradição tornam-se uma ética que, no entanto, não impede que crise da literatura se acentue.

Palavras-chave: Clarice Lispector, representação, alteridade. 


\begin{abstract}
The cockroach, in A paixão segundo G.H., 1964, and Macabéa, in A hora da estrela, 1977, are the radical emphasis on what resists of being captured by word and also they have distinct effects in the writing of the works. By joining language, alterity and subjectiveness, the essay analyzes comparatively the function that word assumes in each of the mentioned works. This function conducts to the possibility or to the impossibility to represent the real and to a possible consequent melancholization. In $A$ paixão segundo G.H., the protagonist narrator is faced with the impossibility of representation. This imposibility, through the configuration of a true fragmentation poetics, acquires a dimension of revelation and liberation. In $A$ hora da estrela, the word, facing the character which can not become the subject of enunciation but nevertheless does not fully associate to the biological, becomes impotent and, however, is impossible to be silenced. The fragmentation and the contradiction become an ethics which, however, does not stop the crisis of literature becomesacute.
\end{abstract}

Key-words: Clarice Lispector, representation, alterity.

\title{
REFERÊNCIAS
}

ARÊAS, Vilma. O resto da metafísica. In: FILIZOLA, Anamaria. Verdade, amor ,razão, merecimento: coisas do mundo e de quem nele anda. Curitiba: UFPR, 2005.

BLANCHOT, Maurice. O espaço literário. Tradução de: Álvaro Cabral. Rio de Janeiro: Rocco, 1987.

BRANCO, Lúcia Castello. Os absolutamente sós: Llansol - a letra - Lacan. Belo Horizonte: Autêntica; FALE/UFMG, 2000.

DERRIDA, Jacques. De l'hospitalité. Paris: Calmann-Lévy, 1997.

GAGNEBIN, Jeanne Marie. Não contar mais? In: História e narração em Walter Benjamin. São Paulo: Fapesp/Perspectiva, Campinas: Unicamp, 1994.

LACAN, Jacques. A instância da letra no inconsciente. In: .Escritos. Tradução de: Vera Ribeiro. Rio de Janeiro: Zahar, 1998.

LAMBOTTE, Marie-Claude. Estética da melancolia . Tradução de: Procopio Abreu. Rio de Janeiro: Companhia de Freud, 2000.

LISPECTOR, Clarice. A paixão segundo G.H. (1964) Rio de Janeiro: Rocco, 1998a. (1973) Água viva. Rio de Janeiro: Rocco, 1998b. (1977) A hora da estrela. Rio de Janeiro: Rocco, 1998c. 
SILVA, F. T. X. Impossibilidade e impotência: trajetórias da...

PONTIERI, Regina. Clarice Lispector: uma poética do olhar. São Paulo: Ateliê Editorial, 1999.

PRADO JR., Plínio. O impronunciável: notas sobre um fracasso sublime. Remate de males, Campinas, n. 9, 1989.

SELIGMANN-SILVA, Márcio. Riso e rubor: o sujeito nos limites do corpo. Prolegômenos para uma filosofia do corpo. Corpolinguagem: gestos e afetos. Campinas: Mercado de Letras, 2003. 